\title{
8
}
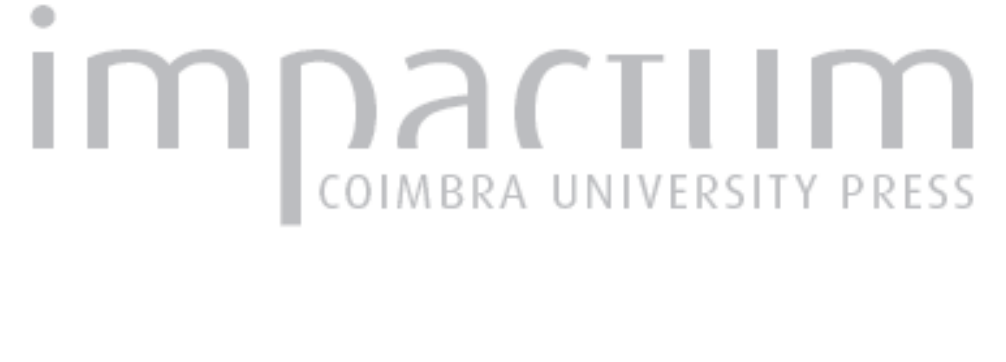

Troianas: do filme de Michael Cacoyannis à tragédia de Eurípides

Autor(es): Werner, Christian

Publicado por: Annablume Clássica

URL persistente:

URI:http://hdl.handle.net/10316.2/24402

DOI:

DOI:http://dx.doi.org/10.14195/1984-249X_7_13

Accessed : $\quad$ 26-Apr-2023 11:28:04

A navegação consulta e descarregamento dos títulos inseridos nas Bibliotecas Digitais UC Digitalis, UC Pombalina e UC Impactum, pressupõem a aceitação plena e sem reservas dos Termos e Condições de Uso destas Bibliotecas Digitais, disponíveis em https://digitalis.uc.pt/pt-pt/termos.

Conforme exposto nos referidos Termos e Condições de Uso, o descarregamento de títulos de acesso restrito requer uma licença válida de autorização devendo o utilizador aceder ao(s) documento(s) a partir de um endereço de IP da instituição detentora da supramencionada licença.

Ao utilizador é apenas permitido o descarregamento para uso pessoal, pelo que o emprego do(s) título(s) descarregado(s) para outro fim, designadamente comercial, carece de autorização do respetivo autor ou editor da obra.

Na medida em que todas as obras da UC Digitalis se encontram protegidas pelo Código do Direito de Autor e Direitos Conexos e demais legislação aplicável, toda a cópia, parcial ou total, deste documento, nos casos em que é legalmente admitida, deverá conter ou fazer-se acompanhar por este aviso.

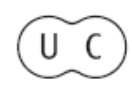


jul.2011

issn 2179-4960

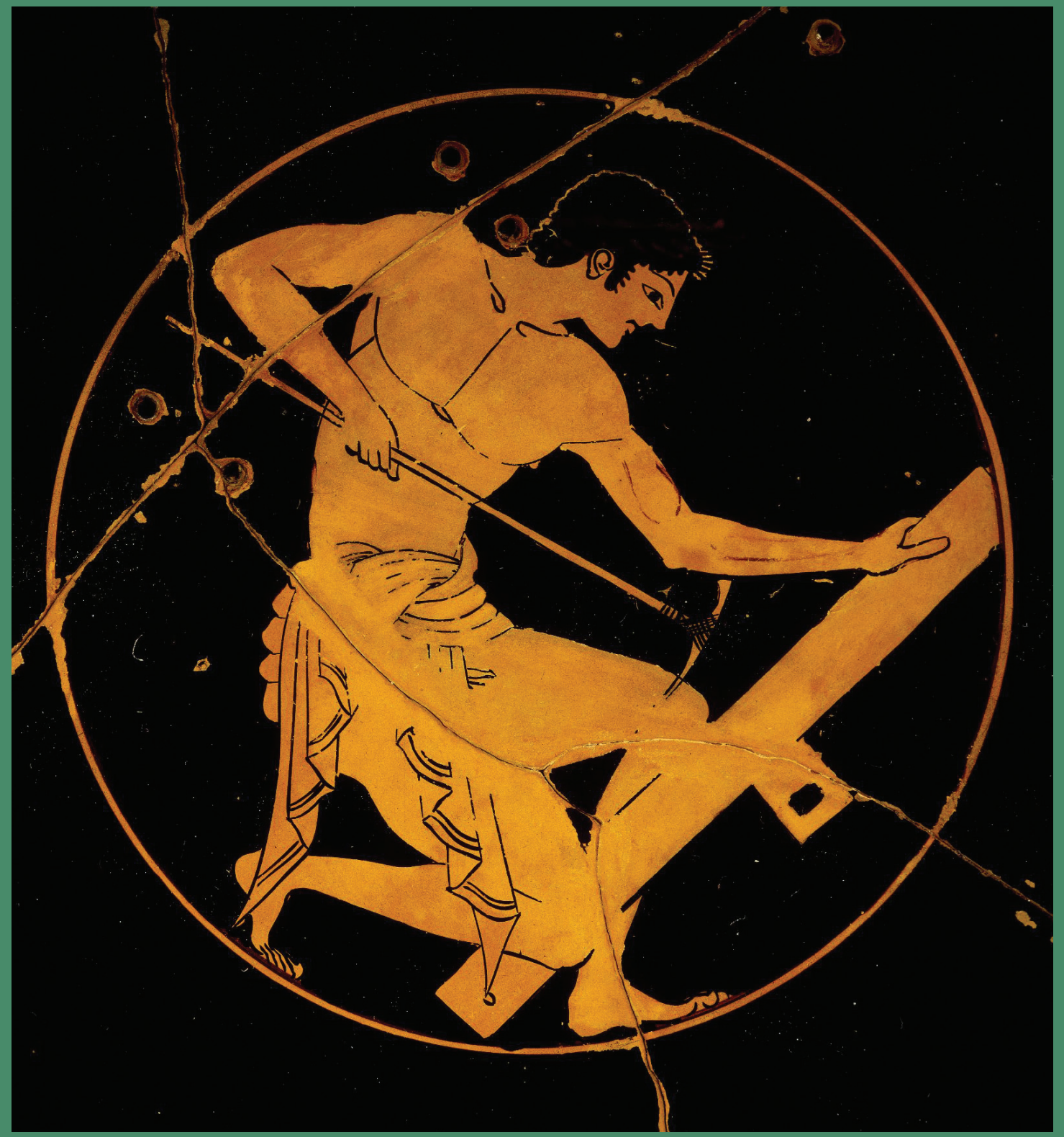

R E V I S T A

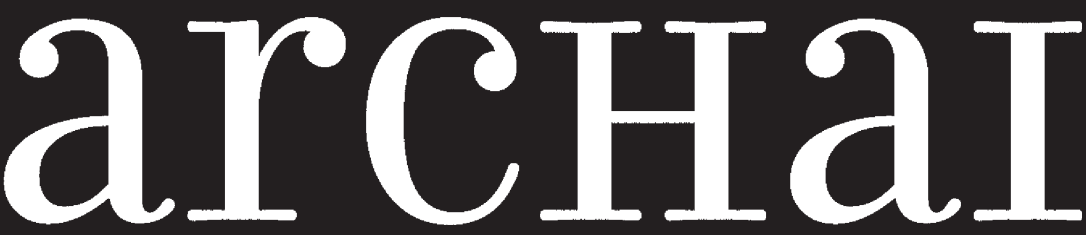

AS ORIGENS DO PENSAMENTO OCIDENTAL

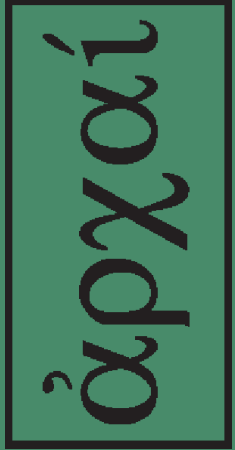

archaI

AS ORIGENS DO PENSAMENTO OCIDENTAL 


\section{TROIANAS: DO FILME DE MICHAEL CACOYANNIS À TRAGÉDIA DE EURÍPIDES}

WERNER, C. (2011). "Troianas: do filme de Michael Cacoyannis à tragédia de Eurípides". Archai n. 7, jul-dez 2011, pp. 131-136.

RESUMO: Busca-se apontar algumas diferenças fundamentais entre a tragédia Troianas, de Eurípides, e a versão que lhe foi dada no filme homônimo de Michael Cacoyannis. Elementos próprios da religião grega mostram que a tragédia de Eurípides não tem, em seu centro, as mensagens políticas univocas propostas por certas adaptações modernas.

PALAVRAS CHAVE: Euripides - Michael Cacoyannis Troianas - religião Grega

TROJAN WOMEN: FROM MICHAEL CACOYANNIS' FILM TO EURIPIDES' TRAGEDY

ABSTRACT: In this paper are explored some basic differences between Euripides' Trojan Women and the cinematic version by Michael Cacoyannis. The religious agenda shows that Euripides' tragedy does not have in its center univocal political messages typical of some of its modern versions.

KEYWORDS: Euripides - Michael Cacoyannis - Trojan Women - Greek religion

\section{Christian Werner*}

* Professor de Língua e Literatura Grega da Universidade de São Paulo. E-Mail: crtwerner@hotmail.com
Pode ser que existam forças demoníacas dentro e fora de nós, preparadas para nos destruírem; pode ser que acabemos na escuridão, no desespero e no suicídio. E faz parte da

dignidade de um homem e de uma mulher olhar de frente esta possibilidade: saber, pelo menos, que tal pode acontecer. As maiores tragédias gregas ensinam-nos constantemente essa possibilidade de pesadelo (George Steiner, para Fogo Grego, de Oliver Taplin)

Algumas das mais instigantes filmagens de obras literárias, de modo especial, dos clássicos, são aquelas que ou bem incorporam deliberadamente temáticas e preocupações contemporâneas ou bem procuram transcender tanto a própria época quanto aquela que marcou a obra de origem. As Troianas (The Trojan Women, 1971), de Michael Cacoyannis (1922-), pertence ao primeiro grupo.

A ação do filme grego segue muito de perto a ação da tragédia homônima escrita por Eurípides em 415 a.C. Logo após o final da guerra de Troia, 
os gregos, que exterminaram toda a população masculina da cidade, à exceção dos meninos, deliberam acerca da distribuição de uma parte dos despojos de guerra, as esposas dos nobres troianos, destinadas a ser escravas e concubinas em terra estrangeira. A ação da tragédia desdobrase em torno dos anúncios das deliberações dos gregos.

Cassandra, filha do casal real troiano, Príamo e Hécuba, é escolhida por Agamêmnon, o líder grego, como sua concubina, pois ela, profetisa de Apolo ao qual o deus prometera a virgindade por toda vida, era um prêmio bastante valioso. Andrômaca, a zelosa esposa de Heitor, o principal herói troiano, será desposada por Neoptólemo, filho de Aquiles, justamente o algoz de Heitor; além disso, Astíanax, o único filho de Andrômaca, julgado ameaçador pelos gregos, que temem que ele possa vir a reerguer a cidade no futuro, será imediatamente executado. Entre as prisioneiras troianas, encontra-se também Helena, esposa de Menelau, rei de Esparta e irmão de Agamêmnon. Ela viera até Troia com Páris, príncipe troiano, fuga ou rapto que deu origem à guerra. Menelau vem buscá-la no acampamento das mulheres, e seu passado e futuro são discutidos: foi culpada pela guerra? Será punida ou poupada pelo marido? Assistindo a tudo isso e discutindo com as personagens envolvidas, Hécuba, obrigada a ver desgraça acumulando-se sobre desgraça, as últimas das quais são o funeral do neto e o derradeiro incêndio da cidade.

A chave de interpretação proposta por Cacoyannis para sua releitura de Eurípides é explicitada na dedicatória final do filme: "aos que são contra a opressão do homem pelo homem". No centro do filme está a postura criminosa do poderoso conquistador masculino contra mulheres e crianças inocentes e indefesas. Isso já transparece nos créditos iniciais, exibidos num fundo vermelho, cor do sangue e do fogo que abre e fecha o filme, cujo cenário é o deserto, que tem, por sua vez, a função de realçar a esterilidade da violência do agressor. ${ }^{1}$

É pouco provável que o cineasta cipriota não tenha sido influenciado pela adaptação do texto de Eurípides feita por Jean-Paul Sartre para a televisão em 1965. ${ }^{2}$ Assim como Cacoyannis, o filósofo e dramaturgo francês carrega nas tintas para descrever negativamente o furor guerreiro do invasor; cadáveres e fogo pululam no seu texto. Sartre trabalhou o texto grego influenciado pela recente independência da Algéria, que teve como um dos seus momentos mais importantes o maciço ataque dos franceses contra a resistência algeriana que se constitui em meados da década de 1950 na Casbah, centro de Argel. Em 1966, tais eventos foram narrados por Gillo Pontecorvo, cineasta de esquerda europeu no filme $A$ batalha de Argel (La Bataglia di Algeri). ${ }^{3}$

Já o trabalho de Cacoyannis é marcado pelo discurso pacifista do final da década de 1960, manifestado particularmente no repúdio à guerra do Vietnã. Procurando defender uma interação possivel entre povos diversos, Cacoyannis escolhe grandes atrizes de diferentes países para interpretar as personagens femininas do seu filme: Irene Papas (Helena), Geneviève Bujold (Cassandra), Vanessa Redgrave (Andrômaca) e Katharine Hepburn (Hécuba).

0 viés escolhido pelo diretor já fica claro no prólogo do seu filme, que inicia com o relato de um narrador onisciente que não só abrevia bastante o texto de Eurípides, mas também condena os gregos por sua violência e ganância, condenação apoiada pelas imagens. Sartre, ao contrário de Cacoyannis, manteve as duas personagens divinas que abriam o drama, Poseidon e Atena. 0 deus marítimo, porém, não só abre, mas, ao contrário do que ocorre na versão de Eurípides, também fecha essa adaptação, condenando os gregos - e o invasor de modo geral. Assim, ambas as releituras tornam-se maniqueístas e unívocas. Elas trazem uma mensagem política clara: a condenação de todas as guerras e de todas as formas de espoliação.

Ao examinar-se o prólogo do texto de Eurípides verifica-se que a leitura do cineasta passa ao largo de uma série de temas nucleares da tragédia. 0 que primeiro chama a atenção quando o comparamos aos das outras tragédias restantes de Eurípides é que ele tem uma série
1. Nesse sentido, o espaço e fotografia escolhidos pelo diretor estão de acordo com a imagem que a personagem que abre a tragédia de Eurípides, 0 deus Poseidon, utiliza para evocar o ambiente da tragédia: “Matas desertas e de deuses mansões / descambam em sangue" (15-16). A tradução desses versos e de outros neste texto é minha e está no livro 'Troianas' e 'Hécuba' de Eurípides (EURIPIDES, 2004).

2. Acerca desse trabalho de Sartre, cf. Loraux (LORAUX, 1999, p. 10 e segs.).

3. 0 filme de Pontecorvo é uma condenação tão virulenta da ocupação francesa que teve de ser retirado dos cinemas de Paris em virtude das ameaças de organizações de direita. 
de elementos destoantes dos demais prólogos, em especial, o anúncio de acontecimentos futuros para além do tempo dramático, ou seja, ele se assemelha ao final de várias tragédias.

Tendo em vista que, no êxodo, um deus amiúde anuncia o futuro diretamente ou por meio de uma personagem humana, talvez uma pergunta vizinha seja mais pertinente: o que fazem os deuses no prólogo? Poseidon, de um lado, vem se despedir da sua cidade, cujas muralhas ele ajudou a construir pessoalmente. Atena, por outro lado, vem anunciar uma vingança contra os gregos, já que Cassandra foi agarrada à força pelo herói grego Ájax no templo da deusa. A segunda pergunta, portanto, emerge desse inédito encontro: por que dois deuses olimpicos abrem a tragédia em conjunto?

0 monólogo introdutório de Poseidon permite não somente que os espectadores se localizem espacial e temporalmente - a função principal de todos os prólogos trágicos atenienses, especialmente os de Eurípides -, mas também frisa a desolação de Troia, a qual é potencializada pela separação iminente entre um deus e a cidade que the é cara: "nunca de meu espírito, contra a

4. A sintaxe ambivalente do texto grego, que procure reproduzir na tradução, reforça os laços entre o deus e o povo que o honrava. cidade, partiu o afeto por meus frígios" (6-7). ${ }^{4}$

Isso é fundamental para que fique claro ser um engano tentar encontrar na fala do deus motivos para uma sua vingança contra os gregos. Nenhum sacrilégio foi cometido contra ele. Quando ele menciona que "ao pé da base do altar de Zeus Caseiro, Príamo está prostrado, morto" (16-17), ele se refere, em primeiro lugar, ao fato que a cidade está aniquilada. 0 cadáver do rei, fundamento político da cidade, encontra-se sobre o altar de Zeus, fundamento religioso. A expressão que traduzi por "ao pé da base do altar" é "pròs báthrois". Não por acaso báthros reaparece no final do monólogo, quando Poseidon diz que, da cidade, nada mais se encontra sobre seus fundamentos: “Assim, adeus, ó cidade um dia afortunada e muralha torneada: se não te tivesse aniquilado Palas, filha de Zeus, ainda estarias de pé (en báthrois)". 0 altar, onde toda a cidade, imaginariamente, começa, também é o ponto final metafórico de Troia.
Nesse sentido, Poseidon demonstra resignação, já que um deus não se enluta: isso é deixado para os humanos. De modo algum, porém, o deus sente raiva. Ele lamenta o destino funesto da cidade e se prepara para partir, temendo o contato com algo impuro. 0 universo divino é de permanente festa, como o próprio deus fala no início, ao marcar, desde logo, a separação entre o mundo dos imortais e o dos mortais: “Eu, Poseidon, chego após deixar o salgado Egeu, o fundo do mar, onde coros de Nereidas desenlaçam do pé o mais belo rastro" (1-3).

Por conseguinte, não só estamos longe de uma condenação em bloco dos vencedores, mas sim de uma explicitação da diferenciação entre humanos e deuses, que permeará todo o drama. De fato, uma representação ou investigação daquilo que seja o humano pode ser apontado como o vetor principal não somente dessa tragédia, mas de todo o gênero.

A partida de Poseidon é retardada pela chegada de Atena. A marca mais saliente da primeira parte do diálogo entre os deuses que segue é a troca de farpas, ocasionada pela simpatia de um por Troia, do outro, pelos gregos. A querela entre os dois, entretanto, é de imediato dissolvida, e para isso há apenas um motivo: Atena, uma deusa, foi desrespeitada; a Poseidon, um deus, cabe auxiliá-la na recuperação da reverência dos mortais. Dessa forma, o diálogo mostra que os deuses não estão reagindo para punir ofensas de humanos contra humanos, mas sim que os homens são castigados por agirem desrespeitosamente em relação aos deuses. Os gregos serão punidos porque ultrapassaram os limites estabelecidos pelos deuses, de sorte que eles revelarão toda sua força. Os deuses - não apenas Atena, mas também Poseidon e Zeus agem não porque os gregos tenham cometido crimes que a justiça exige fossem punidos, mas porque a honra dos deuses foi atingida.

Dessa forma é acentuada a distância entre deuses e humanos. A rápida reconciliação entre Poseidon e Atena mostra os deuses bastante próximos entre si e muito longe dos homens. 
Ambos os deuses são escolhidos para abrir a tragédia a fim de que se represente a separação irremediável entre um deus e o grupo humano que lhe é caro: Poseidon, dos troianos; Atena, dos gregos. Consequentemente, é justamente a ênfase na distância entre mortais e imortais que é enunciada nos versos que encerram a participação dos deuses: "Louco é o mortal que saqueia cidades, templos e túmulos, dos finados o sagrado: talando-os, ele perecerá depois" (9597).

Esse trecho tem problemas gramaticais e semânticos que, ao se tornarem questão de acirrada discussão entre os helenistas, revelam que a passagem é decisiva para que compreenda a tragédia. Compete, basicamente, analisar se 0 que está em julgamento é a guerra e suas consequências ou uma atitude mais genérica, a saber, o comportamento dos mortais em relação à divindade, ao imortal.

Pontuando-se após "talando-os", enfatizase a característica essencial do homem, sua mortalidade ("perecerá"). Esse mortal comete 0 erro de subverter a ordem religiosa, divina: 0 homem é "louco" porque se crê imortal. Poseidon não se refere somente à descrição de Troia arrasada, mas também à fala de Atena, que, após ajudar os gregos posteriormente fora vilipendiada pelos vencedores. Os gregos, em termos objetivos, se acreditaram superiores à sua condição mortal. De fato - e isso é fundamental para a desconstrução de uma visão maniqueísta do drama -, a fala de Poseidon também alude ao próprio comportamento dos troianos em relação aos deuses. Como fica claro ao longo da tragédia, eles confiaram excessivamente numa bemaventurança eterna.

Daí, se compararmos o início da adaptação de Sartre e com aquele do filme de Cacoyannis, podemos concluir que: (1) a teologia presente na tragédia não mais faz sentido para os modernos, e por isso é eliminada da representação; ${ }^{5}$ e (2) os deuses de Sartre e o narrador onisciente de Cacoyannis, ao invés de deixarem aos mortais a busca pelo que esses, de fato, são, impingem juízos peremptórios sobre os negócios humanos.
Mesmo a guerra e seus procedimentos tem regras; aliás, Atena também é uma deusa guerreira. 0 que os deuses condenam é o mortal que ultrapassa tais regras. Mesmo que seja uma questão muito genérica e, para muitos, ultrapassada, o drama trata daquilo que é humano, que tem, como sua componente fundamental, os limites do homem em relação aos deuses.

Outra passagem emblemática para se compreender a distância que separa o texto de Eurípides das suas releituras contemporâneas é o episódio de Cassandra, talvez uma das mais impactantes cenas escritas pelo tragediógrafo. Trata-se de uma composição bastante complexa, não só pela sua riqueza cênica e musical, mas também pela relação com um episódio de vigor equivalente de outra tragédia fulcral do século $\mathrm{V}$ a.C., o Agamêmnon, de Ésquilo.

0 que nos mostra o filme? Uma jovem totalmente indefesa, já que louca, sendo perseguida por soldados comandados por Taltíbio, 0 arauto grego que funciona como intermediário entre o local onde estão as mulheres e o acampamento dos chefes. Já no drama é a própria Cassandra, sozinha, que sai de dentro da cabana onde está presa. Novamente, o objetivo central de Cacoyannis é reiterar a imagem do homem como agressor e da mulher como sua vítima. No filme, as coisas estranhas que Cassandra faz, como dançar com fachos, apenas remete para sua loucura. No drama, indicam que sua loucura é relativa, ou melhor, que suas ações são determinadas por sua razão e por seu caráter. No filme, por exemplo, a dança em uma caverna que servia de templo de Apolo é representada como imprópria. Já na tragédia, a dança é, ao mesmo tempo, natural, já que efetuada na orquestra, o lugar da dança numa representação trágica, mas, segundo a ótica de Hécuba e das cativas - e esse relativismo é fundamental -, imprópria, já que o momento é de dor. Ora, tal combinação ambivalente - dança/ canto e lágrimas, prazer e dor - constitui o cerne mesmo do espetáculo trágico.

Tanto no filme de Cacoyannis quanto em Eurípides, o anúncio da morte de Astíanax para a
1 Por outro lado, os deuses são muito bem utilizados por JeanLuc Godard na sua desconstrução da Odisseia em 0 desprezo ( $L \hat{e}$ Mépris, 1963); já Wolfgang Petersen decidiu igualmente deixar de lado os deuses na sua adaptação da Ilíada em Tróia (Troy, 2004), embora a impiedade seja um tema do filme. 
sua mãe, Andrômaca, é o clímax da ação. Da mesma forma, a cena seguinte, o episódio de Helena, compõe em ambas as criações uma espécie de anti-clímax e, não por acaso, foi eliminada da adaptação teatral de Antunes Filho, Fragmentos troianos, de 1999, a qual remetia, por sua vez, para grandes genocídios do século $X X$, dos campos de concentração alemães às guerras nos Bálcãs.

As diferenças entre o filme e o texto de Eurípides, entretanto, não poderiam ser maiores. Assim como a morte da criança representa o auge da violência irracional, a cena de Helena, ao levar ao paroxismo a vaidade da rainha, reforça que a causa da guerra foi totalmente estúpida. Enquanto as prisioneiras morrem de sede sob o sol abrasivo, Helena, com a água que recebe do guarda que a vigia, lava, arrogantemente, seu belo corpo. A esterilidade da beleza e, portanto, da sexualidade, não poderia ser melhor representada. Em Eurípides, porém, a beleza de Helena e a beleza de forma geral, bem como o desejo por ela gerado, não tem a mesma carga negativa de leituras modernas da tragédia.

0 intermezzo coral que antecede a cena menciona alguns troianos bem-aventurados que suscitaram o desejo dos deuses. A intenção do coro, porém, é mostrar que a beleza que motivou o contato privilegiado desses troianos com os deuses não teve utilidade alguma para Troia, ou seja, para o coro a dimensão divina do belo tornase uma variável intangível, incompreensível. Dessa forma, instaura-se o problema que compõe o núcleo do episódio seguinte, o debate entre Hécuba e Helena: como devem ser valorizados a beleza e o desejo por ela evocados? Somente num universo divino antropomorfizado, como aquele das epopeias homéricas, uma personagem como Helena é valorizada? Como avaliar a tentativa de invocação de uma teologia purificada por parte de Hécuba?

6. 0 casamento era a função primeira da mulher ateniense; vale salientar que ele é um dos principais elementos dos discursos de todas as personagens femininas da tragédia. possivveis da sedução masculina. Afrodite, a seu turno, a deusa invocada por Helena para justificar seu comportamento pretérito, é deslocada para um céu donde, tranquila, não se move. $\mathrm{Na}$ verdade, a formulação de Hécuba aproxima a rainha das deusas Hera e Atena, as adversárias de Troia, e a afasta de Afrodite, a aliada da cidade!

Entretanto, se compararmos os comentários feitos pelas personagens do drama, veremos que não se apresenta uma construção rígida da figura do casamento. Andrômaca e Helena não se restringem a consubstanciar, respectivamente, a esposa ideal e a adúltera que arrasa tudo o que toca; ambas incorporam, nas suas respectivas vidas conjugais, faces diversas do casamento. Andrômaca e Heitor formaram um casal ideal; as virtudes de ambos, entretanto, causaram suas desgraças e a do filho. 0 casamento entre Menelau e Helena foi manchado pelo adultério da esposa; a tradição, porém, os mostra unidos para todo o sempre, gozando da vida eterna na Ilha dos Bem Aventurados. De ambos os casamentos, portanto, faz parte a reversão da fortuna. Eles não se encontram tão distanciados entre si.

No fundo, a própria Hécuba compreende e maneja tal realidade, por exemplo, quando solicita às suas duas noras que procedam de modos diversos em situações semelhantes. Antes de ser anunciada a morte de Astíanax, Hécuba solicita a Andrômaca que faça uso da sedução em vista do seu novo marido, que ela, a princípio, execra, a fim de que, no futuro, Astíanax possa reerguer a cidade. Já no caso de Helena, a sedução é censurável; ela deveria cobrir-se somente com os trapos da vergonha ao se apresentar a Menelau.

0 casamento revela-se uma esfera onde 0 acaso, a týkhe, pode irromper. A cega obediência ao que seja a excelência para a mulher levou Andrômaca direto para a ruína, pois ela se tornou, graças à virtude, um prêmio cobiçado pelos gregos. Quanto a Helena, como a týkhe, ela parece estar em constante movimento, tomando decisões e mudando de opinião, adequando-se a fatos novos quando necessário e deles fazendo o melhor 
proveito possível, o que, entretanto, não implica que não esteja, na maior parte das vezes, trilhando o fio da navalha entre a censura e o louvor.

Percurso semelhante é o de Odisseu, herói grego que não participa da ação propriamente dita da tragédia, embora dele se fale diversas vezes ao longo do drama, de modo especial, ao ser comparado a Heitor. É ele, por exemplo, que convence os gregos a matarem Astíanax, e usando um modo de pensar semelhante ao que desenvolve Hécuba ao longo de toda a tragédia. A rainha indica ser prudente que o homem, ao agir e sentir, não leve em consideração apenas o presente, mas também o passado e o futuro. É de tal prudência que faz uso Odisseu ao defender a morte de Astíanax. De fato, tanto Odisseu quanto a deusa que, sobretudo na tradição épica, costuma protegê-lo, Atena, são mencionados nas Troianas para realçar a ubiquidade e o modo de atuação da týkhe, que, por sua vez, não diferencia vencedores e derrotados. 0 mesmo vale para Helena, que também é uma personagem que se comporta como týkhe.

Concluindo, o drama de Eurípides não se preocupa, em primeiro lugar, em denunciar a capacidade destrutiva do homem, mas em encenar uma situação limite em que o homem é obrigado a encarar a perda de tudo aquilo sobre o qual se apoiava a sua vida. Os bens humanos mostramse, na sua essência, vulneráveis. Hécuba, Cassandra e Andrômaca não podem mais exercer as atividades que conferiam significado às suas vidas. Mesmo assim - e é exatamente isso que compõe o que há de maravilhoso e terrível nessa tragédia -, elas perseguem, in extremis, alguma ação ou discurso que reafirme o seu valor. 0 fim de suas ações, entretanto, é ambíguo, já que a morte e a týkhe são onipresentes. Aliás, é justamente o acaso e as reversões da fortuna que indicam que Odisseu e Helena não são "vilões" sem nuances, mas personagens ambivalentes. Ao contrário das troianas, eles não procuram trazer a eternidade ao mundo humano: ao conseguirem retornar para suas casas, eles demonstram ser possivel navegar de acordo com o inusitado trazido pela týkhe.
Todavia, tanto Helena quanto Odisseu são incapazes de sentir piedade pelas troianas, ou seja, eles não compreendem a dor que toma conta de seus inimigos e que, por outro lado, eles mesmos poderiam estar nessa situação. $\mathrm{Na}$ tragédia, a única personagem capaz de sentir piedade, essa rara virtude que, desde a Ilíada, também constitui a excelência do herói, é Taltíbio. Essa, aliás, não é única característica que aproxima o mensageiro de uma função regularmente atribuída ao coro em um texto trágico. 0 coro composto pelas troianas está indissociavelmente ligado a Hécuba. Já Taltíbio, devido ao seu movimento pendular, pode captar lados diversos da mesma ação, mesmo que os tinja - e isso também é típico de um coro - com as cores próprias do homem comum, ou seja, ele vê os acontecimentos como nós, que não somos heróis, os vemos. Taltíbio representa aquilo que tanto o coro quanto os espectadores de uma tragédia precisam fazer: tentar compreender 0 que se passa em cena. 0 que, no seu caso, confere-lhe um valor suplementar é que ele se aproxima, efetivamente, das derrotadas, ao sentir com elas o drama que as atinge e ao tentar agir dentro das suas possibilidades.

Já as personagens femininas dessa tragédia, mais do que heroínas passivas ou vilãs de folhetim, ao mesmo tempo que afirmam ser obrigadas a viver e compreender uma situação presente que elas, por uma série de razões, contrapõem a uma situação passada, que pretendem ser diametralmente oposta, também se deparam com uma inquietante e perturbadora contiguidade entre o passado e o presente, de tal sorte que a percepção dessa ligação acaba por apontar para uma terceira situação possível, a qual, essa sim, acena para um futuro diferente do nada, da destruição radical. É nesse sentido que a própria existência da tragédia, como espetáculo e como vivência das suas personagens, e também o seu final, por assim dizer, aberto impedem que seja apresentado uma quadro final niilista. Ao passo que a guerra, em Cacoyannis, implicando a representação da dor causada pela total impotência, conduz a um luto infinito não apaziguável, em 
Eurípides, para além da guerra, pode-se compreender as causas da impotência presente, de sorte que, ao se assumir a impotência como própria, reconquista-se algum valor. 0 luto - medo e piedade - é gerado, mas encontra-se acompanhado, para quem quer ouvi-lo, do discurso que procura apaziguá-lo: sentimento.

Recebido em junho de 2011, aprovado em junho de 2011.

\section{REFERÊNCIAS BIBLOGRÁFICAS E CINEMATOGRÁFICAS}

\section{Referências primárias}

CACOYANNIS, M . (1972). As troianas (The Trojan Women). Grécia/USA/UK.

EURIPIDES (2004). Troianas e Hécuba de Eurípides. Tradução do grego Christian Werner. São Paulo: Martins Fontes.

\section{Referências secundárias}

GODARD, J-L. (1963). 0 desprezo (Le Mépris). França. PETERSEN, W. (2004). Troia (Troy). Estados Unidos. LORAUX, N. (1999). La voix endeuillée. Paris: Gallimard. PONTECORVO, G. (1966). A batalha de Argel (La Bataglia di Algeri). Itália.

TAPLIN, 0 (1990). Fogo Grego. Trad. Jorge Pires et alii. Lisboa: Gradiva. 